\title{
Using Neural Networks to Determine the Significance of Aggregate Characteristics Affecting the Mechanical Properties of Recycled Aggregate Concrete
}

\author{
Zhenhua Duan ${ }^{1,2}$, Shaodan Hou ${ }^{1}$, Chi-Sun Poon ${ }^{2, *}$, Jianzhuang Xiao ${ }^{1}$ and Yun Liu ${ }^{1, *}$ \\ 1 Department of Structural Engineering, Tongji University, Shanghai 200092, China; \\ zhduan@tongji.edu.cn (Z.D.); hsd2017@tongji.edu.cn (S.H.); jzx@tongji.edu.cn (J.X.) \\ 2 Department of Civil and Environmental Engineering, The Hong Kong Polytechnic University, Hung Hom, \\ Kowloon, Hong Kong, China \\ * Correspondence: cecspoon@polyu.edu.hk (C.-S.P.); liuyun@tongii.edu.cn (Y.L.); \\ Tel.: +852-2766-6024 (C.-S.P.); +86-21-6598-3320 (Y.L.)
}

Received: 29 September 2018; Accepted: 1 November 2018; Published: 6 November 2018

check for updates

\begin{abstract}
It has been proved that artificial neural networks (ANN) can be used to predict the compressive strength and elastic modulus of recycled aggregate concrete (RAC) made with recycled aggregates from different sources. This paper is a further study of the use of ANN to analyze the significance of each aggregate characteristic and determine the best combinations of factors that would affect the compressive strength and elastic modulus of RAC. The experiments were carried out with 46 mixes with several types of recycled aggregates. The experimental results were used to build ANN models for compressive strength and elastic modulus, respectively. Different combinations of factors were selected as input variables until the minimum error was reached. The results show that water absorption has the most important effect on aggregate characteristics, further affecting the compressive strength of RAC, and that combined factors including concrete mixes, curing age, specific gravity, water absorption and impurity content can reduce the prediction error of ANN to $5.43 \%$. Moreover, for elastic modulus, water absorption and specific gravity are the most influential, and the network error with a combination of mixes, curing age, specific gravity and water absorption is only $3.89 \%$.
\end{abstract}

Keywords: recycled aggregate; recycled aggregate concrete; artificial neural networks; aggregate characteristic; input variable

\section{Introduction}

There is no doubt that the utilization of recycled aggregate concrete (RAC) has been the best way to resolve the problem of the increasing amount of construction and demolition (C\&D) waste and further attain sustainable development. The improved environmental performance of recycled aggregate concrete (RAC) [1-3] has led to research on recycled aggregate (RA) and RAC, a popular topic in the last decades [4-7]. Recycled coarse aggregate and recycled fine aggregate were both used in concrete to make full use of $C \& D$ wastes; meanwhile, the cementitious materials supplied, such as fly ash and silica fume, were used together with RA for high-performance RAC [8-11]. Though there has been a large amount of research on the properties of RAC, the results have been varied because the properties of RAs from different sources (such as the demolition of bridges, buildings and airport pavements) and produced using different recycling methods (e.g., the type and effort of the crushers used) vary greatly [12]. It is generally accepted that the properties of RA and the hardened properties of RAC made with such RA are both largely affected by the nature of the attached old mortar [13-17]. However, it is difficult to establish an accurate relationship between the two, since at present there is 
no established method for accurately measuring the quantity and quality of the attached mortar in RA. On the other hand, RAs may also contain impurities, such as bricks, glass, tiles, asphalt, plastics, gypsum, wood and clay, etc. In small amounts, however, their presence may seriously deteriorate the quality of RA. The presence of other impurities makes it more complicated to predict the properties of RAC.

Therefore, there are at least two major difficulties in building a model that can predict the performance of hardened RAC made with RAs from different sources: (1) the model should act as an expert system covering the factors that may affect the properties of RAC, such as cement content, water to cement ratio, aggregate to cement ratio, cement type and particle size of aggregates, etc.; (2) an optimal combination of RA characteristics should be included in the model so that it can be applicable to the majority of RAs from different sources. A previous study [18] used regression analysis to propose a number of equations relating the hardened properties (compressive strength) of RAC with the water absorption or density of different types and combinations of aggregates obtained from different sources. However, the accuracy of the prediction is limited since the properties of RA cannot be completely represented by the density or water absorption values of RA. Tam and Tam [19] suggested that there were six main factors that characterize the properties of RA: (1) particle size distribution; (2) particle density; (3) porosity and absorption; (4) particle shape; (5) strength and toughness; and (6) chloride and sulphate contents. Through a comparison and analysis of ten sources of RAs and one type of natural aggregate (NA), they constructed relationships among these factors and indicated that the RA properties could be assessed by only measuring three of the six parameters mentioned. However, whether the model is suitable for RAs obtained from other sources has not been verified.

As a modeling tool, artificial neural networks (ANN) have been widely used since the mid-1980s, and have also been demonstrated to have superior capacities in modeling more complex relationships. Among all the ANN structures, the back-propagation network (BPN) is generally regarded as one of the simplest and most applicable networks used in simulating concrete properties. As shown in Figure 1, a typical BPN model consists of an input layer, one or more hidden layers and an output layer, and each layer consists of numerous neurons. During the training set, feed-forward propagation and back-propagation propagation run in turn to reach the required criteria. The former propagation can first transform the input mode onto the hidden layer, and then pass the weighted sum of inputs to the output layer through an activation function, resulting in one output value. In this stage, the sigmoidal function $(f()$.$) is generally used, and the output can be calculated according to Equation$ (1). Immediately after that, the back-propagation propagation works by passing the error of network backwards from the output layer to the input layer, with the weights adjusted based on some learning strategies to reduce the network error.

$$
f_{j}=\frac{1}{1+\exp \left(-\sum w_{j i} o_{i}+b\right)}
$$

where $w_{j i}$ is the connection weight from neuron $i$ in the lower layer to neuron $j$ in the upper layer and an initially small random value, $o_{i}$ is the output of neuron $i$, and $b$ is the bias value. 


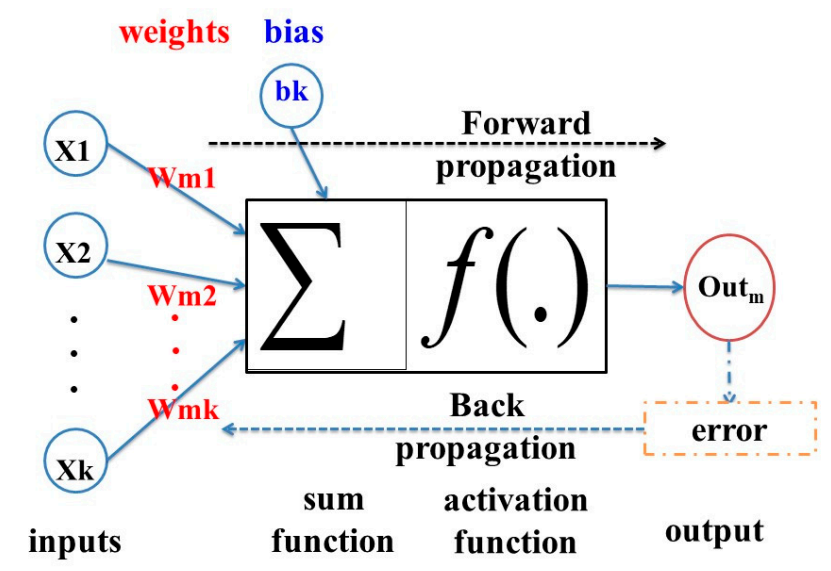

Figure 1. A typical artificial neural networks (ANN) model.

Duan et al. [20] carried out a study on predicting the compressive strength of RAC at the curing time of 28 days using an ANN model. The authors collected a large amount of published data on the 28-day compressive strength of RAC, which came from previous research. The RA used was derived from different countries and sources. The data were used for the construction of the ANN model, and the predicted results of the ANN model were quite accurate. Moreover, the same author also established another ANN model for predicting the elastic modulus of RAC [21]. This model was built based on regression analysis and performed better predictions. Sensitivity analysis, an uncertainty analysis technique in relation to quantitative analysis, is a study to assess the sensitivity of the prediction results of the model to the change in the selected input variables [22]. It also determines the significance of these uncertain factors on the results [23-25]. Therefore, it is of interest to apply the sensitivity analysis to the constructed ANN model to further study the influence of each input variable on the output. By conducting a sensitivity analysis, Jain et al. [26] determined the effect of the constituents of concrete mixes on the desired workability.

To predict the compressive strength of NAC (natural aggregate concrete) using ANN, the concrete mix proportions used [27-30] and the time of testing of the compressive strength [31-33] were generally selected as the input variables. For concrete made with RAs from different sources, the difference between the properties of different RAs should be taken into account. The aggregate characteristics, such as water absorption, specific gravity, and aggregate crush value are closely related to the properties of the old mortar attached, which can affect the properties of RAC by different levels. In theory, the more factors are taken into consideration, the more accurate the model is. However, in practice it is unsuitable to use all the affected factors due to the complicated calculation and the measuring error. Therefore, it is important to determine the significance of each RA characteristic and the optimal combination of factors, which aims to ensure the factors can be applicable to the majority of RAs from different sources. In other words, how to fully represent the aggregate properties in the ANN model is an important issue.

The purpose of this study is to examine the relative importance of the different characteristics of RA in affecting RAC properties. Moreover, it also aims to determine which factor or combination of factors is most suitable for representing RA properties when used in ANN model for compressive strength and elastic modulus prediction. In this study, the following steps were used for this purpose.

\section{Methodologies}

\subsection{Building the ANN Models and the Sensitivity Analysis}

First, experiments on the mechanical properties of RAC with different RAs were carried out in the laboratory, which had 46 concrete mixes and were divided into 3 groups. The RAs were categorized into 3 groups according to their sources: (1) RAs derived from 3 different sources and crushed 
using different methods; (2) RAs derived from concrete cubes made in the laboratory with different compressive strengths (35-85 MPa); (3) RAs contained different amounts of masonry added (clay bricks or tiles). As many sources of natural and recycled aggregates were used in these mixes, 8 aggregate characteristics, including fineness modulus of the fine aggregate $(F M)$, residual mortar content $\left(\mathrm{M}_{\mathrm{C}}\right)$, $10 \%$ fines value $(\mathrm{TFV})$, aggregate crushing value $(\mathrm{ACV})$, water absorption value $\left(\mathrm{W}_{\mathrm{a}}\right)$, specific gravity (SGSS), impurity content $(\delta)$ and masonry content $(\mathrm{m})$ of the coarse aggregate, were comprehensively measured and quantified. These factors, together with the mix proportions and concrete curing time, were selected as the input variables of the ANN for modeling the compressive strength and elastic modulus. To facilitate the analysis, factors including the mix proportions ( 5 variables) and curing time (1 variable) were designated as "certainties", while the other factors (8 variables) were named "uncertainties".

The experimental results obtained from the above mixes at different ages were divided into three groups, acting as: (i) the training set; (ii) the validation set; and (iii) the testing set, respectively. The corresponding ANN model could be established using the procedures described previously [20]. For each model, the ANN network parameters were determined when the error values reached the minimum. Based on the comparison of the error of integral testing set after a series of trials, the initial network architecture and parameters used in this study were as follows:

- $\quad$ Number of input layer units $=14$

- $\quad$ Number of hidden layers $=1$

- Number of hidden layer units $=40$

- Number of output layer units $=1$

- $\quad$ Momentum rate $=0.9$

- $\quad$ Learning rate $=0.01$

- $\quad$ Learning cycle $=15,000$

In this study, the mean absolute percentage error (MAPE), root-mean-squared error (RMS) and absolute fraction of variance $\left(R^{2}\right)$ computed using Equations (2)-(4) were used to access the accuracy of the ANN model developed.

$$
\begin{gathered}
M A P E=\left(\frac{o_{j}-t_{j}}{o_{j}}\right) \\
R M S=\sqrt{\frac{1}{p} \times \sum_{j}\left|t_{j}-o_{j}\right|^{2}} \\
R^{2}=1-\left(\frac{\sum_{j}\left|t_{j}-o_{j}\right|^{2}}{\sum_{j}\left(o_{j}\right)^{2}}\right)
\end{gathered}
$$

where $t$ : the predicted output of the network; $o$ : the actual output of the network; $p$ : the total number of training and testing patterns; $t_{j}$ : the predicted output of $j$ th pattern of the network; $o_{j}$ : the actual output of $j$ th pattern of the network.

After the construction of the ANN models, the sensitivity analysis was then conducted according to Figure 2. 


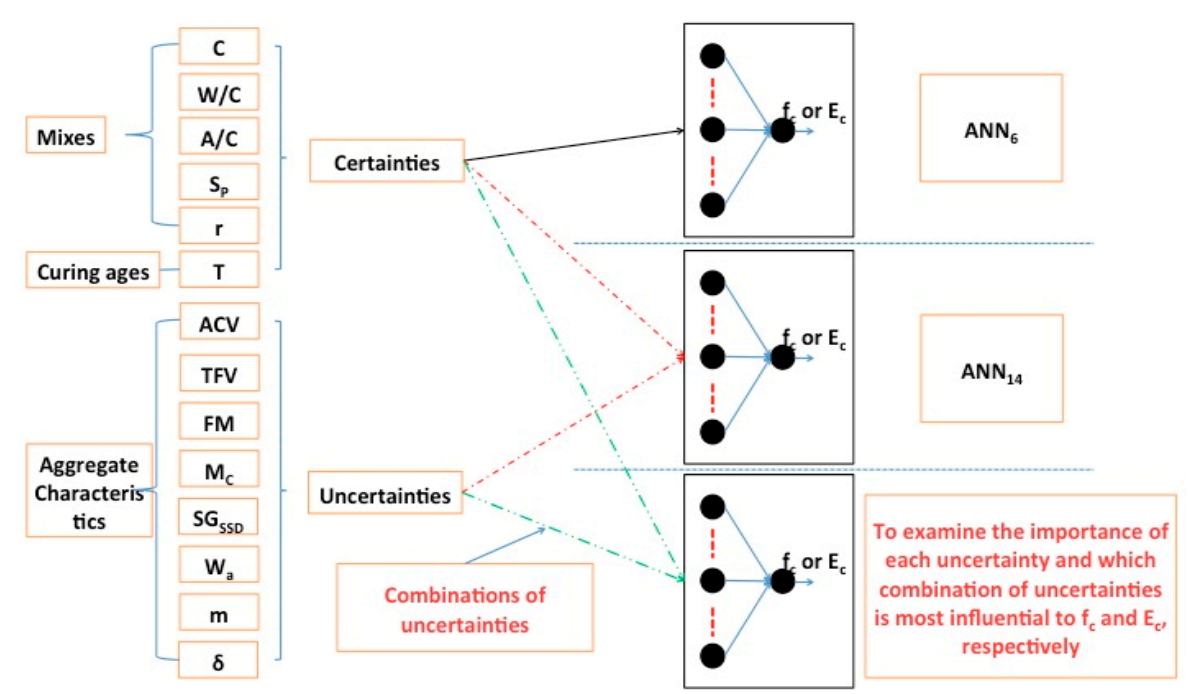

Figure 2. Flow chart of the sensitivity analysis

Step 1: A comparison of the performance between the models $\left(A N N_{14}\right)$ with all variables (14 variables) and that $\left(A N N_{6}\right)$ with certainties (only 6 variables) was first made, while keeping the other networks parameters constant.

Step 2: Various combinations of the uncertainties (aggregate characteristics) together with the "certainties" were used as the inputs of each model to find the best model with the minimum error. However, it would take a huge amount of time if all the combinations were tried out one by one. Considering the interaction and constraints among the aggregate characteristics, a simple method developed to determine the best combination of variables is shown in Figure 3.

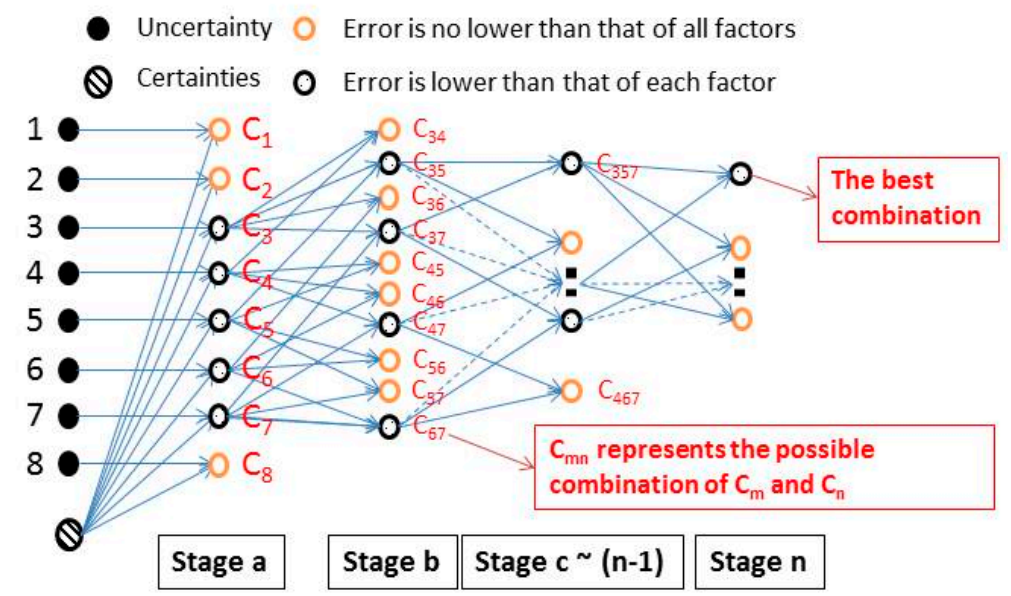

Figure 3. The determination of the best combination of input variables.

- At Stage a, the resulted error of $A N N_{6}$ was compared with that of the networks $\left(A N N_{7}\right)$ when each "uncertainty" was sequentially added as an input variable. If the error could not be reduced, then the "uncertainty" added was regarded as negative for the output and would not be further studied in the next stages. The larger the reduction in the error value, the more important the respective "uncertainty", and vice versa.

- At Stage b, the variables that could reduce the error of $A N N_{6}$ were retained. Sequentially, each variable was paired with the others as the added inputs of $A N N_{6}$ to build a new model $\left(A N N_{8}\right)$, and the resulted error values were compared with those of the networks $\left(A N N_{7}\right)$ when only one variable was added to $A N N_{6}$. If the resulted error of the $A N N_{8}$ was not less than that of each $A N N_{7}$, the pair of variables was not further studied. For example, as shown in Figure 3, 
in the further right column, items 3 and 4 represent two aggregate characteristics, respectively. Accordingly, C3 and C4 (in the second right column) represent a combination of "certainty" variables with items 3 and 4, respectively. Assuming that the addition of either item 3 or item 4 to the certainties could reduce the network error of $A N N_{6}, \mathrm{C} 3$ and $\mathrm{C} 4$ would be both retained and used to form a new combination C34, which contained 8 input variables (items 3, 4 and certainties). When comparing the MAPE values of the networks using C $34, \mathrm{C} 3$ and $\mathrm{C} 4$ as inputs, respectively, and if the first one was lower than both the latter two values, C34 would be retained for the next stage. Otherwise, it would be discarded.

- This above approach was continued until the networks error could not be further reduced. In this way, after trying out all the possible combinations, the most influential factor or a combination of factors to the compressive strength and elastic modulus of RAC could be identified.

Considering that the predicted results of the networks would change slightly even when using the same model, each of the networks was trained 5 times and the average value of the MAPEs of the testing set and validation set was used as the final indicator of the network error.

\subsection{Experimental Program}

It is not necessary to use ANN to model the effect of RA on the properties of RAC when only one type of RA is used, since in this case the complexity of RA cannot be reflected and the predictive ability of ANN is generally no better than that of traditional methods like regression analysis.

When RAs from different sources were used, ANN models, which are more capable of modeling complex non-linear relationships, may be more suitable for predicting the hardened properties of RAC. The published data of RAs used can be divided into two cases: (1) several types of RAs used by a single researcher; (2) the data of RAs from different literature sources. The factors that influence the properties of RAC and used as the input variables of the networks in the two cases are quite different. For the former case, the types of materials other than aggregate, specimen size and operator error are essentially the same, so only the mix proportions and RA characteristics are chosen as the input variables; for the latter case, on the other hand, in addition to the mix proportions and RA characteristics, more factors such as cement type, specimen size, etc. should be included to establish a generalized model. In this paper, only the first case is considered. The second case will be dealt with in a separate paper.

(1) The source of the data

As introduced above, experiments on the mechanical properties of RAC with different RAs were carried out in the laboratory, which had 46 concrete mixes and were divided into 3 groups. The properties of these aggregates are shown in Table 1. Except for the chosen aggregate characteristics, the particle size was also listed in Table 1 for different aggregate types. The details of the mixes and the corresponding hardened properties of the concrete prepared are shown in Tables 2 and 3, respectively.

Table 1. Properties of aggregates.

\begin{tabular}{|c|c|c|c|c|c|c|c|c|c|c|}
\hline \multirow{2}{*}{ Sources } & Aggregate & Particle Size & $\mathrm{SG}_{S S D}$ & $\mathbf{W}_{\mathbf{a}}$ & $\mathbf{M}_{\mathbf{c}}$ & $\operatorname{ACV}(\%)$ & TFV (KN) & m & $\delta$ & \multirow{2}{*}{ FM } \\
\hline & Type & $\mathrm{mm}$ & $\mathrm{g} / \mathrm{cm}^{3}$ & $\%$ & $\%$ & $10-14 \mathrm{~mm}$ & $10-14 \mathrm{~mm}$ & $\%$ & $\%$ & \\
\hline \multirow{5}{*}{ Source 1} & NA1 & 20 & 2.6 & 1.01 & 0 & 21.7 & 155 & 0 & 0 & / \\
\hline & RA1 & 20 & 2.48 & 3.36 & 21 & 22.5 & 143 & 1.4 & 0.4 & / \\
\hline & RA2 & 20 & 2.36 & 6.14 & 35.1 & 23.4 & 133 & 2.9 & 1.1 & / \\
\hline & RA3 & 20 & 2.36 & 6.44 & 62 & 23.9 & 127 & 1 & 0 & / \\
\hline & FNA1 & 5 & 2.63 & 0.94 & 0 & / & / & 0 & 0 & 2.19 \\
\hline
\end{tabular}


Table 1. Cont

\begin{tabular}{|c|c|c|c|c|c|c|c|c|c|c|}
\hline \multirow{2}{*}{ Sources } & Aggregate & Particle Size & $\mathrm{SG}_{\mathrm{SSD}}$ & $\mathbf{W}_{\mathbf{a}}$ & $\mathbf{M}_{\mathbf{c}}$ & $\operatorname{ACV}(\%)$ & TFV (KN) & $\mathbf{m}$ & $\delta$ & \multirow{2}{*}{ FM } \\
\hline & Type & $\mathbf{m m}$ & $\mathrm{g} / \mathrm{cm}^{3}$ & $\%$ & $\%$ & $10-14 \mathrm{~mm}$ & $10-14 \mathrm{~mm}$ & $\%$ & $\%$ & \\
\hline \multirow{4}{*}{ Source 2} & NA2 & 20 & 2.66 & 0.71 & 0 & 15.8 & 259 & 0 & 0 & / \\
\hline & RA5 & 20 & 2.42 & 5.18 & 0 & 19.7 & 154 & 0 & 0 & / \\
\hline & RA6 & 20 & 2.44 & 5.36 & 0 & 19.5 & 151 & 0 & 0 & / \\
\hline & RA7 & 20 & 2.45 & 5.3 & 0 & 20.3 & 147 & 0 & 0 & / \\
\hline \multirow{5}{*}{ Source 3} & NA1 & 20 & 2.6 & 1.01 & 0 & 21.7 & 155 & 0 & 0 & / \\
\hline & NA2 & 20 & 2.66 & 0.71 & 0 & 15.8 & 259 & 0 & 0 & / \\
\hline & RA9 & 20 & 2.49 & 3.85 & 22 & 21.5 & 149 & 2 & 1.1 & / \\
\hline & brick & 20 & 1.99 & 21.74 & 0 & 27.1 & 44 & 100 & 100 & / \\
\hline & tile & 10 & 2.03 & 14.82 & 0 & 19.1 & 105 & 100 & 100 & / \\
\hline
\end{tabular}

NA1-NA2, RA1-RA9, FNA1-FNA3 represent natural coarse aggregate, recycled coarse aggregate, and natural fine aggregate from different sources or batches, respectively. SGSSD: specific gravity; $W_{\mathrm{a}}$ : water absorption value; $\mathrm{M}_{\mathrm{c}}$ : residual mortar content; ACV: aggregate crushing value; TFV: 10\% fines value; FM: fineness modulus.

Table 2. Mix proportions of recycled aggregate concrete (RAC) made with aggregates from different sources $\left(\mathrm{kg} / \mathrm{m}^{3}\right)$.

\begin{tabular}{|c|c|c|c|c|c|c|c|}
\hline Sources & Mixes & $\mathbf{W}$ & Cement & Sand & NA & RA & Aggregate Used \\
\hline \multirow{20}{*}{ Source 1} & NA30 & 205 & 300 & 697 & 1143 & 0 & NA1 \\
\hline & RC30-1 & 205 & 300 & 697 & 0 & 1075 & RA1 \\
\hline & RC30-2 & 205 & 300 & 697 & 0 & 1027 & RA2 \\
\hline & RC30-3 & 205 & 300 & 697 & 0 & 1027 & RA3 \\
\hline & NC45 & 180 & 350 & 706 & 1158 & 0 & NA1 \\
\hline & RC45-1 & 180 & 350 & 706 & 0 & 1089 & RA1 \\
\hline & RC45-2 & 180 & 350 & 706 & 0 & 1041 & RA2 \\
\hline & RC45-3 & 180 & 350 & 706 & 0 & 1041 & RA3 \\
\hline & NA60 & 185 & 425 & 696 & 1092 & 0 & NA1 \\
\hline & RC60-1 & 185 & 425 & 696 & 0 & 1028 & RA1 \\
\hline & RC60-2 & 185 & 425 & 696 & 0 & 982 & RA2 \\
\hline & RC60-3 & 185 & 425 & 696 & 0 & 982 & RA3 \\
\hline & NA80 & 165 & 485 & 685 & 1089 & 0 & NA1 \\
\hline & RC80-1 & 165 & 485 & 685 & 0 & 1039 & RA1 \\
\hline & RC80-2 & 165 & 485 & 685 & 0 & 979 & RA2 \\
\hline & RC80-3 & 165 & 485 & 685 & 0 & 982 & RA3 \\
\hline & MC45-2 & 180 & 350 & 675 & 0 & 1089 & RA2 \\
\hline & MC45-3 & 180 & 350 & 654 & 0 & 1041 & RA3 \\
\hline & MC60-2 & 185 & 425 & 637 & 0 & 1028 & RA2 \\
\hline & MC60-3 & 185 & 425 & 618 & 0 & 982 & RA3 \\
\hline \multirow{6}{*}{ Source 2} & NAC & 155 & 440 & 666 & 1166 & 0 & NA2 \\
\hline & $\mathrm{R} 30$ & 155 & 440 & 666 & 0 & 1070 & RA4 \\
\hline & R45 & 155 & 440 & 666 & 0 & 1077 & RA5 \\
\hline & R60 & 155 & 440 & 666 & 0 & 1083 & RA6 \\
\hline & R80 & 155 & 440 & 666 & 0 & 1090 & RA7 \\
\hline & R100 & 155 & 440 & 666 & 0 & 1094 & RA8 \\
\hline \multirow{11}{*}{ Source 3} & Control & 190 & 380 & 710 & 1110 & 0 & NA2 + FNA3 \\
\hline & $\mathrm{T} 5$ & 190 & 380 & 710 & 1055 & 44 & NA2 + FNA3 + tile \\
\hline & T10 & 190 & 380 & 710 & 999 & 88 & $\mathrm{NA} 2$ + FNA3 + tile \\
\hline & T15 & 190 & 380 & 710 & 944 & 132 & $\mathrm{NA} 2$ + FNA3 + tile \\
\hline & b5 & 190 & 380 & 710 & 1055 & 43 & NA2 + FNA3 + brick \\
\hline & b10 & 190 & 380 & 710 & 999 & 86 & NA2 + FNA3 + brick \\
\hline & b15 & 190 & 380 & 710 & 944 & 129 & NA2 + FNA3 + brick \\
\hline & b5r50 & 185 & 370 & 732 & 545 & 481 & NA1 + RA9 + FNA2 + brick \\
\hline & b5r100 & 185 & 370 & 732 & 0 & 961 & RA9 + FNA2 + brick \\
\hline & b10r50 & 185 & 370 & 732 & 545 & 475 & NA1 + RA9 + FNA2 + brick \\
\hline & b10r100 & 185 & 370 & 732 & 0 & 948 & RA9 + FNA2 + brick \\
\hline
\end{tabular}


Table 2. Cont.

\begin{tabular}{cccccccc}
\hline Sources & Mixes & W & Cement & Sand & NA & RA & Aggregate Used \\
\hline b15r50 & 185 & 370 & 732 & 545 & 526 & NA1 + RA9 + FNA2 + brick \\
b15r100 & 185 & 370 & 732 & 0 & 1049 & RA9 + FNA2 + brick \\
T5r50 & 185 & 370 & 732 & 545 & 486 & NA1 + RA9 + FNA2 + tile \\
T5r100 & 185 & 370 & 732 & 0 & 970 & RA9 + FNA2 + tile \\
T10r50 & 185 & 370 & 732 & 545 & 511 & NA1 + RA9 + FNA2 + tile \\
T10r100 & 185 & 370 & 732 & 0 & 1018 & RA9 + FNA2 + tile \\
ro & 185 & 370 & 732 & 1090 & 0 & NA1 + FNA2 \\
r50 & 185 & 370 & 732 & 545 & 463 & NA1 + RA9 + FNA2 \\
r100 & 185 & 370 & 732 & 0 & 924 & RA9 + FNA2 \\
\hline
\end{tabular}

NA: natural aggregate; RA: recycled aggregate.

Table 3. Mechanical properties of RAC.

\begin{tabular}{|c|c|c|c|c|c|c|c|c|}
\hline \multirow{2}{*}{ Sources } & \multirow{2}{*}{ Mixes } & \multicolumn{5}{|c|}{$f_{c}(\mathrm{MPa})$} & \multicolumn{2}{|c|}{$E_{c}(\mathrm{GPa})$} \\
\hline & & 1 Day & 4 Days & 7 Days & 28 Days & 90 Days & 28 Days & 90 Days \\
\hline \multirow{20}{*}{ Source 1} & NA30 & & & & 34.5 & 39.4 & 25.1 & 26.6 \\
\hline & RC30-1 & & & & 35 & 39.8 & 20.85 & 25.18 \\
\hline & RC30-2 & & & & 29.2 & 34 & 21.9 & 22.83 \\
\hline & RC30-3 & & & & 27.7 & 28.4 & 20.49 & 21.5 \\
\hline & NC45 & & & & 48.3 & 53 & 30.68 & 31.1 \\
\hline & RC45-1 & & & & 47.6 & 51.3 & 28.86 & 30.68 \\
\hline & RC45-2 & & & & 42 & 47 & 24.46 & 25.91 \\
\hline & RC45-3 & & & & 42.9 & 46.3 & 26.55 & 27.22 \\
\hline & NA60 & & & & 61.6 & 69.6 & 32.36 & 34.5 \\
\hline & RC60-1 & & & & 60 & 67.7 & 29.42 & 33.42 \\
\hline & RC60-2 & & & & 53.7 & 55.5 & 24.61 & 26.3 \\
\hline & RC60-3 & & & & 53.2 & 58.6 & 28.5 & 27.94 \\
\hline & NA80 & & & & 80.5 & 88.3 & 35.43 & 36.88 \\
\hline & RC80-1 & & & & 78.2 & 84.1 & 34.76 & 35.49 \\
\hline & RC80-2 & & & & 71.2 & 74.3 & 29.52 & 29.92 \\
\hline & RC80-3 & & & & 65.4 & 73.3 & 30.62 & 30.74 \\
\hline & RC45-1 & & & & 49.2 & 51.5 & 29.5 & 31.2 \\
\hline & RC45-2 & & & & 43.6 & 50.1 & 25.48 & 26.35 \\
\hline & RC60-1 & & & & 60.4 & 68 & 30.7 & 33.6 \\
\hline & RC60-2 & & & & 57.3 & 62.7 & 26.99 & 27.3 \\
\hline \multirow{6}{*}{ Source 2} & NAC & 29.3 & 54.8 & 59.7 & 69.6 & 75.3 & 32.3 & 36.1 \\
\hline & $\mathrm{R} 30$ & 24 & 50.7 & 54.1 & 59.4 & 63 & 27.43 & 28.67 \\
\hline & $\mathrm{R} 45$ & 31 & 56 & 60.2 & 69.8 & 76.3 & 27.26 & 30.9 \\
\hline & R60 & 22.9 & 50.1 & 57.6 & 67.8 & 74.8 & 27.02 & 30.98 \\
\hline & R80 & 24.8 & 52.6 & 59.4 & 68.7 & 72.7 & 26.85 & 30 \\
\hline & R100 & 20.1 & 46.5 & 55.2 & 62.1 & 66.3 & 26.79 & 28.48 \\
\hline \multirow{13}{*}{ Source 3} & Control & & & & 54.4 & 60.5 & 29.85 & 31.51 \\
\hline & $\mathrm{T} 5$ & & & & 54.4 & 59.9 & 28.42 & 30.94 \\
\hline & $\mathrm{T} 10$ & & & & 54.9 & 60 & 27.44 & 29.14 \\
\hline & $\mathrm{T} 15$ & & & & 52.5 & 57.6 & 27.09 & 28.08 \\
\hline & b5 & & & & 54.2 & 59.4 & 27.49 & 30.27 \\
\hline & b10 & & & & 52.3 & 57.6 & 25.46 & 28.05 \\
\hline & b15 & & & & 46.9 & 54.8 & 23.18 & 24.24 \\
\hline & b5r50 & 18.6 & $38.2^{a}$ & 41.7 & 48.4 & 54.1 & 29.03 & 30 \\
\hline & b5r100 & 15.9 & $34.7^{\mathrm{a}}$ & 35 & 44 & 45.9 & 27.1 & 27.9 \\
\hline & b10r50 & $25.3^{b}$ & & 39.1 & 47.5 & 54 & 27 & 28.26 \\
\hline & b10r100 & $23.9^{b}$ & & 34.6 & 42.4 & 45.4 & 26.69 & 27.85 \\
\hline & b15r50 & 21.6 & 37.5 & 38.8 & 46.7 & 50.5 & 24.42 & 26.14 \\
\hline & b15r100 & 17.5 & 31.5 & 33.9 & 41.1 & 42.1 & 24.15 & 25.58 \\
\hline
\end{tabular}


Table 3. Cont.

\begin{tabular}{|c|c|c|c|c|c|c|c|c|}
\hline \multirow{2}{*}{ Sources } & \multirow{2}{*}{ Mixes } & \multicolumn{5}{|c|}{$f_{c}(\mathrm{MPa})$} & \multicolumn{2}{|c|}{$E_{c}(\mathrm{GPa})$} \\
\hline & & 1 Day & 4 Days & 7 Days & 28 Days & 90 Days & 28 Days & 90 Days \\
\hline & T5r50 & 20 & $34.9^{c}$ & 41.4 & 49.1 & 54 & 27.39 & 30.13 \\
\hline & T5r100 & 18.5 & & 36.5 & 44.7 & 47.4 & 25.69 & 26.15 \\
\hline & T10r50 & 19.2 & 37.6 & 42.5 & 50.7 & 52.8 & 26.72 & 28.87 \\
\hline & T10r100 & 14.4 & 28.6 & 34.4 & 39.9 & 42 & 24.55 & 25.55 \\
\hline & r0 & 21.3 & & 42.1 & 48.2 & 51.3 & 30.45 & 33.86 \\
\hline & r50 & 20 & 40.2 & 44.1 & 50.3 & 53.6 & 29.58 & 30.35 \\
\hline & r100 & 18 & 40.1 & 43 & 49.2 & 51.3 & 26.78 & 27.86 \\
\hline
\end{tabular}

(2) Construction of the ANN models

As shown in Table 3, the experiment had a total of 145 and 92 results for compressive strength and elastic modulus, respectively, which were divided randomly into 3 groups used to construct the ANN models. The 3 groups were used as the training, testing and validation sets, respectively. The testing and validation sets were intended to establish the model with the generalization ability. After training, the optimal models for simulating the compressive strength $\left(A N N_{14}-f_{c}\right)$ and elastic modulus $\left(A N N_{14}-E_{c}\right)$ using all 14 variables were constructed (Figure 4), and the network architecture and parameters selected were as follows, in line with the similar procedure previously established [15].

- $\quad$ Number of input layer units $=16$

- $\quad$ Number of hidden layers $=1$

- Number of hidden layer units $=40$

- Number of output layer units $=1$

- $\quad$ Momentum rate $=0.9$

- $\quad$ Learning rate $=0.01$

- $\quad$ Learning cycle $=10,000$

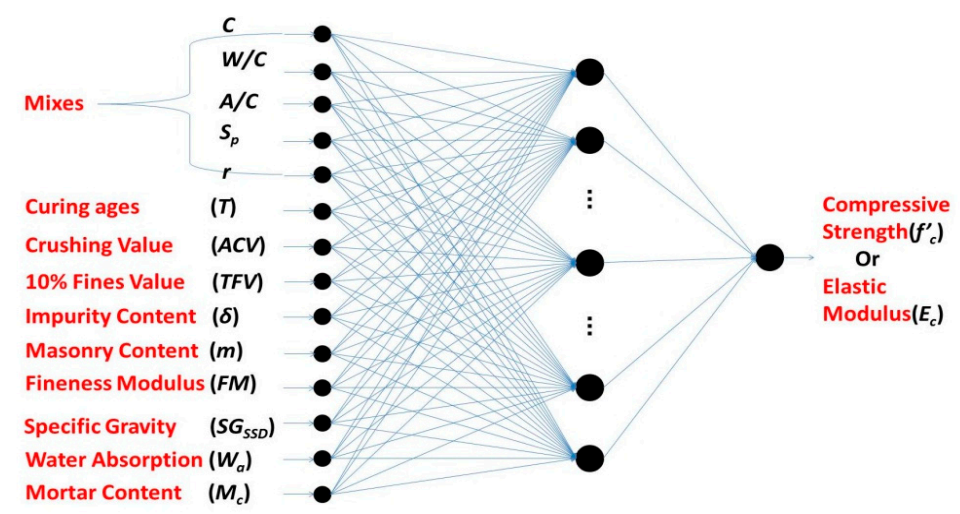

Figure 4. ANN model constructed for compressive strength or elastic modulus.

\section{Results and Discussion}

The performance of the constructed ANN models $\left(A N N_{14}-f_{c}, A N N_{14}-E_{c}\right)$ in predicting the compressive strength and elastic modulus of RAC with all 14 variables and compared to the models $\left(A N N_{6}-f_{c}, A N N_{6}-E_{c}\right)$ using only the "certainties" as input variables is shown in Table 4 and Figure 5. 
Table 4. Performance of ANN models. MAPE: the mean absolute percentage error; RMS: root-meansquared error.

\begin{tabular}{|c|c|c|c|c|c|c|c|c|}
\hline Sets & Model & $R^{2}$ & $R M S$ & MAPE (\%) & Model & $R^{2}$ & $R M S$ & MAPE (\%) \\
\hline Training & & 0.9984 & 2.067 & 3.531 & & 0.9999 & 0.2825 & 0.73 \\
\hline Testing & $A N N_{14}-f_{c}$ & 0.9952 & 3.445 & 5.859 & $A N N_{14}-E_{c}$ & 0.9965 & 1.6986 & 4.72 \\
\hline Validation & & 0.9949 & 3.562 & 6.032 & & 0.9968 & 1.563 & 4.399 \\
\hline Training & & 0.997 & 2.764 & 4.743 & & 0.9941 & 0.9558 & 2.641 \\
\hline Testing & $A N N_{6}-f_{c}$ & 0.987 & 5.234 & 8.67 & $A N N_{6}-E_{c}$ & 0.9931 & 2.3066 & 6.437 \\
\hline Validation & & 0.992 & 4.41 & 7.557 & & 0.9913 & 2.5234 & 7.264 \\
\hline
\end{tabular}

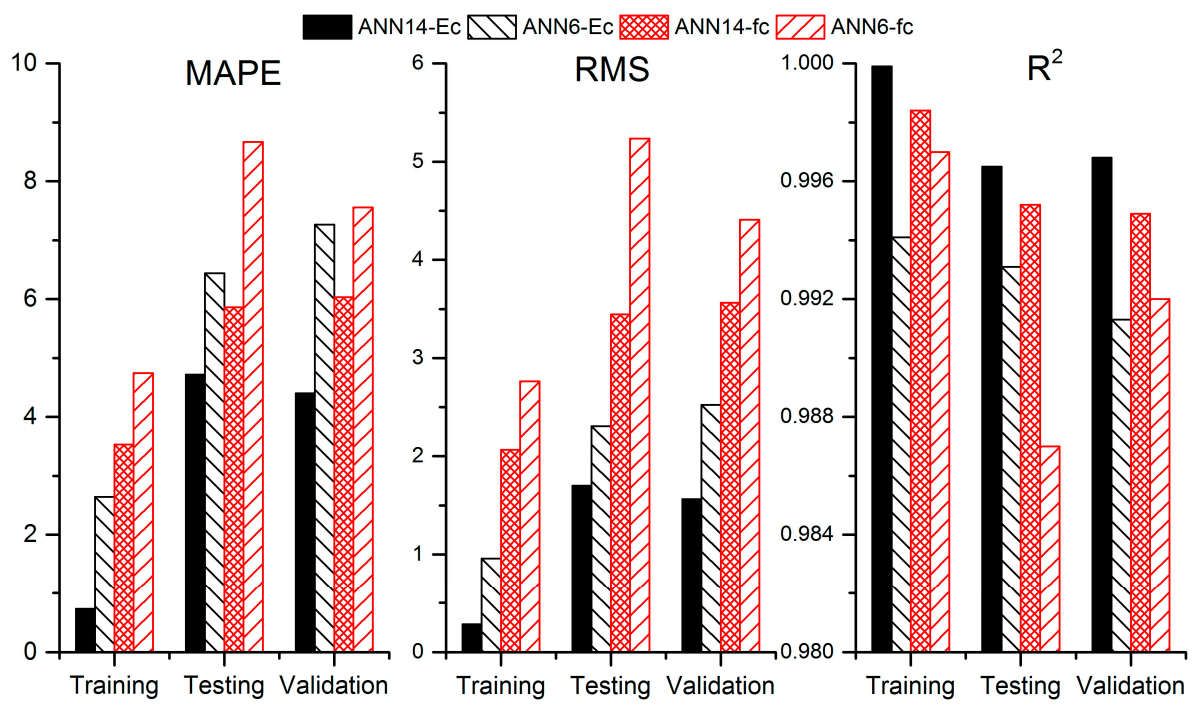

Figure 5. Performance of the ANN models constructed. MAPE: the mean absolute percentage error; RMS: root-mean-squared error.

The correlation coefficient $R^{2}$ of the networks in modeling the compressive strength and elastic modulus reached 0.9984 and 0.9999 , respectively, indicating that the correlations between the predictions and the true results were very good. The $R^{2}$ values of both models were all above 0.994 in the testing and validation sets and these further proved that the constructed models, $A N N_{14}-f_{c}$ and $A N N_{14}-E_{c}$, had not only good simulating abilities, but also good generalization capabilities.

When only the mix proportions and the curing ages were used as the inputs of the networks, the $R^{2}$ values of $A N N_{6}-f_{c}$ and $A N N_{6}-E_{c}$ in the training sets were still up to 0.997 and 0.9941 . However, the generalization performance (testing and validation sets) of both networks were significantly poorer, with the $R^{2}$ values reduced to the range of $0.987-0.9931$ and the predicted errors MAPE increased by about $50 \%$ in both the validation and testing sets. This might explain why many established formulae (based on regression analysis) could not be used for practical applications although they had good correlation coefficients.

For compressive strength, Figure 6 shows that the predicted error of the networks $\left(A N N_{6}-f_{c}\right)$ using only "certainties" as inputs was about $8.11 \%$, and the performance of the networks could be enhanced with the addition of each aggregate characteristic to the inputs. It can be found that the predicted error of compressive strength was lower when the water absorption or masonry content of the coarse aggregate were taken into consideration, which was almost close to the model $\left(A N N_{14}-f_{c}\right)$ with all variables as inputs. 


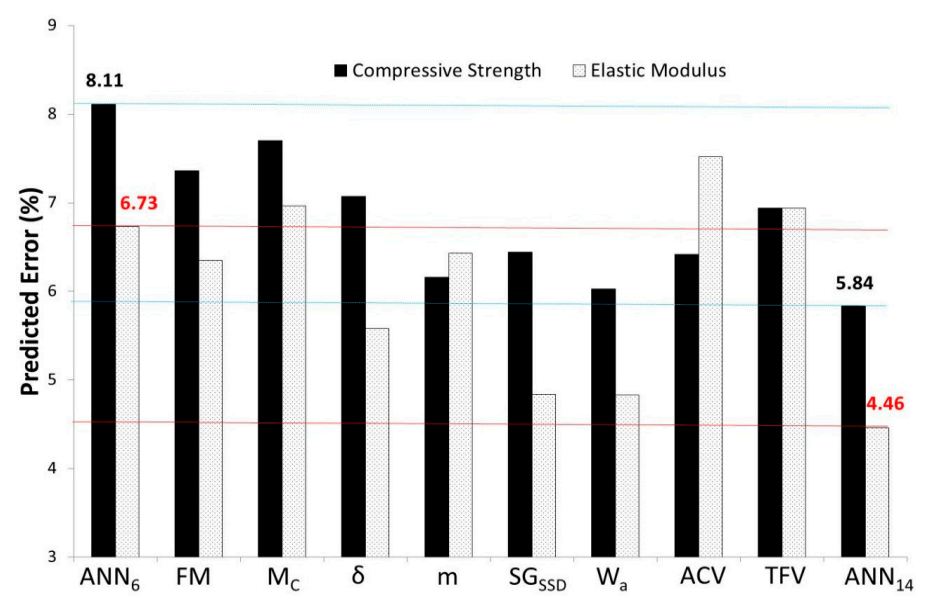

Figure 6. Influence of each uncertainty on the properties of RAC relative to models $\left(A N N_{6}\right)$ with only "certainties" as inputs—Stage a.

As shown in Table 5, the performance of the networks $\left(A N N_{8}\right)$ with the combinations of two aggregate characteristics added as inputs of $A N N_{6}-f_{c}$ was not necessarily better than those with only one aggregate characteristic added to the inputs. This was mainly due to the fact that the degrees of influence related to these aggregate characteristics were inconsistent, which may have misled the correlation of the inputs and outputs. However, the results demonstrated that the use of seven combinations (italics) of aggregate characteristics as inputs to $A N N_{6}-f_{c}$ could improve the predicted capability of the networks; these combinations were $\mathrm{SG}_{S S D}$ and $\mathrm{W}_{\mathrm{a}}, \mathrm{SG}_{\mathrm{SSD}}$ and TFV, $\mathrm{W}_{\mathrm{a}}$ and $\delta, \mathrm{W}_{\mathrm{a}}$ and $\mathrm{TFV}, \mathrm{FM}$ and TFV, $\mathrm{m}$ and $\delta$, and $\mathrm{m}$ and $\mathrm{M}_{\mathrm{c}}$.

Table 5. The errors of networks for compressive strength with different input variables—Stage b (\%).

\begin{tabular}{ccccccccc}
\hline Factors & SG $_{\text {SSD }}$ & $\mathbf{W}_{\mathbf{a}}$ & $\mathbf{F M}$ & $\mathbf{M}_{\mathbf{c}}$ & $\boldsymbol{\delta}$ & $\mathbf{m}$ & $\mathbf{T F V}$ & $\mathbf{A C V}$ \\
\hline $\mathrm{SG}_{\mathrm{SSD}}$ & $\mathbf{6 . 4 4}$ & $\underline{5.94}$ & 6.95 & 7.12 & 6.8 & 7.63 & $\underline{6.11}$ & 6.54 \\
$\mathrm{~W}_{\mathrm{a}}$ & & $\mathbf{6 . 0 3}$ & 6.6 & 6.99 & $\underline{5.76}$ & 6.89 & $\underline{\mathbf{5 . 9 2}}$ & 6.55 \\
$\mathrm{FM}$ & & & $\mathbf{7 . 3 6}$ & 7.34 & $\mathbf{7 . 4 8}$ & 6.91 & $\underline{6.55}$ & 8.02 \\
$\mathrm{M}_{\mathrm{c}}$ & & & & 7.7 & $\underline{5.84}$ & $\underline{5.99}$ & $\mathbf{6 . 9 9}$ & 7.25 \\
$\delta$ & & & & & $\mathbf{7 . 0 7}$ & $\mathbf{6 . 8 8}$ & 8.09 & 7.23 \\
$\mathrm{~m}$ & & & & & & $\mathbf{6 . 1 6}$ & 8.32 & 6.64 \\
$\mathrm{TFV}$ & & & & & & & $\mathbf{6 . 9 4}$ & 6.87 \\
$\mathrm{ACV}$ & & & & & & & & $\mathbf{6 . 4 2}$ \\
\hline
\end{tabular}

For Tables 5-8, each figure represents the mean absolute percentage error (MAPE) value of the networks with "certainties" and the uncertain factors indicated in the 1st row and 1st column as inputs; the bold figures represent the MAPE value of the networks with "certainties" and the uncertain factors indicated either in the 1st row or 1st column as inputs; the underlined figures are MAPE values lower than those of the corresponding bold letters.

Then, these combinations of two characteristics were used to examine whether they could form new combinations of three or four characteristics that could further improve the prediction of the networks. The results listed in Table 6 show that the error of networks could be reduced to 5.43-5.91 when the following combinations of aggregate characteristics, together with "certainties", were adopted as the inputs of networks: $\mathrm{SG}_{\mathrm{SSD}}+\mathrm{W}_{\mathrm{a}}+\delta, \mathrm{SG}_{\mathrm{SSD}}+\mathrm{m}+\mathrm{TFV}+\mathrm{M}_{\mathrm{c}}, \mathrm{SG}_{\mathrm{SSD}}+\mathrm{W}_{\mathrm{a}}+\mathrm{TFV}$ and FM $+\mathrm{m}+$ $\mathrm{TFV}+\mathrm{M}_{\mathrm{c}}$. Moreover, the further combinations of these factors was no longer useful to reduce the error of prediction of the networks (Table 7). 
Table 6. The errors of networks for compressive strength with different input variables—Stage c (\%).

\begin{tabular}{|c|c|c|c|c|c|c|c|}
\hline Factors & $\mathrm{SG}_{\mathrm{SSD}}+\mathrm{W}_{\mathrm{a}}$ & $\mathrm{SG}_{\mathrm{SSD}}+\mathrm{TFV}$ & $\mathbf{W}_{\mathbf{a}}+\delta$ & $\mathbf{W}_{\mathbf{a}}+\mathbf{T F V}$ & FM + TFV & $\mathbf{m}+\delta$ & $\mathbf{m}+\mathbf{M}_{\mathrm{c}}$ \\
\hline $\mathrm{SG}_{\mathrm{SSD}}+\mathrm{W}_{\mathrm{a}}$ & 5.94 & $\underline{5.61}$ & $\underline{5.43}$ & $\underline{5.61}$ & 6.26 & 6.93 & 6.55 \\
\hline $\mathrm{SG}_{\mathrm{SSD}}+\mathrm{TFV}$ & & 6.11 & 6.4 & $\underline{5.61}$ & 6.67 & 6.85 & $\underline{5.53}$ \\
\hline $\mathrm{W}_{\mathrm{a}}+\delta$ & & & 5.76 & 5.81 & 6.33 & 6.52 & 6.16 \\
\hline $\mathrm{W}_{\mathrm{a}}+\mathrm{TFV}$ & & & & 5.92 & 5.96 & 5.96 & 7.87 \\
\hline $\mathrm{FM}+\mathrm{TFV}$ & & & & & 6.55 & 6.8 & $\underline{5.91}$ \\
\hline$m+\delta$ & & & & & & 5.84 & 6.95 \\
\hline$m+M_{c}$ & & & & & & & 5.99 \\
\hline
\end{tabular}

Table 7. The errors of networks for compressive strength with different input variables—Stage d (\%).

\begin{tabular}{ccccc}
\hline Factors & $\mathbf{S G}_{\mathrm{SSD}}+\mathbf{W}_{\mathbf{a}}+\mathbf{T F V}$ & $\mathbf{S G}_{\mathrm{SSD}}+\mathbf{W}_{\mathbf{a}}+\boldsymbol{\delta}$ & $\mathbf{S G}_{\mathrm{SSD}}+\mathbf{m}+\mathbf{T F V}+\mathbf{M}_{\mathbf{c}}$ & $\mathbf{F M}+\mathbf{m}+\mathbf{T F V}+\mathbf{M}_{\mathbf{C}}$ \\
\hline $\mathrm{SG}_{S S D}+\mathrm{W}_{\mathrm{a}}+\mathrm{TFV}$ & $\mathbf{5 . 6 1}$ & 5.91 & 5.93 & 6.07 \\
$\mathrm{SG}_{\mathrm{SSD}}+\mathrm{W}_{\mathrm{a}}+\delta$ & & 5.43 & 5.94 & 6.28 \\
$\mathrm{SG}_{S S D}+\mathrm{m}+\mathrm{TFV}+\mathrm{M}_{\mathrm{c}}$ & & & 5.53 & 6.19 \\
$\mathrm{FM}+\mathrm{m}+\mathrm{TFV}+\mathrm{M}_{\mathrm{c}}$ & & & & $\mathbf{5 . 9 1}$ \\
\hline
\end{tabular}

To sum up, the addition of any one of the eight aggregate characteristics to $A N N_{6}-f_{c}$ could help achieve a better prediction of the compressive strength of RAC. When these characteristics were added to the input variables of $A N N_{6}-f_{c}$ alone, water absorption contributed to the largest reduction in the error of networks, from about $8.11 \%$ to only $6.03 \%$. The use of some combinations of these eight characteristics could further decrease the error of networks, even lower than that of $A N N_{14}-f_{c}$. The network error was only $5.43 \%$ when a combination of $\mathrm{SG}_{\mathrm{SSD}}, \mathrm{W}_{\mathrm{a}}, \delta$, and the "certainties" (mix proportions and curing ages) were used as the input variables.

The case was slightly different for the elastic modulus. As shown in Figure 5, the error of the networks $\left(A N N_{6}-E_{c}\right)$ with only the mix proportions and the curing ages as inputs was about $6.73 \%$. When each one of the eight aggregate characteristics was added to the input variables alone, the results showed that three characteristics (viz mortar content, aggregate crushing value and $10 \%$ fines value) could not improve the prediction, while the other five characteristics could help to optimize the model; among the eight aggregate characteristics, the $\mathrm{SG}_{S S D}$ and $\mathrm{W}_{\text {a }}$ played the most significant influence, being capable of reducing the error to about $4.84 \%$ and $4.83 \%$, respectively.

However, only the combination of $\mathrm{SG}_{\mathrm{SSD}}$ and $\mathrm{W}_{\mathrm{a}}$ could further decrease the network error to about 3.89\%, as shown in Table 8. Therefore, in this study the best combination of parameters for modeling the elastic modulus of RAC was mix proportions, curing ages, and the specific gravity and water absorption values of the RA.

Table 8. The errors of networks for elastic modulus with different input variables—Stage b (\%).

\begin{tabular}{cccccc}
\hline Factors & $\mathbf{M}_{\mathbf{c}}$ & $\mathbf{F M}$ & $\boldsymbol{\delta}$ & $\mathbf{S G}_{\mathbf{S S D}}$ & $\mathbf{W}_{\mathbf{a}}$ \\
\hline $\mathrm{M}_{\mathrm{c}}$ & $\mathbf{6 . 4 3}$ & 6.93 & 6.76 & 5.5 & 5.15 \\
$\mathrm{FM}$ & & $\mathbf{6 . 3 5}$ & 6.98 & 5.01 & 4.94 \\
$\delta$ & & & $\mathbf{5 . 5 8}$ & 5.76 & 5.52 \\
$\mathrm{SG}_{\mathrm{SSD}}$ & & & & $\mathbf{4 . 8 4}$ & $\underline{\mathbf{3 . 8 9}}$ \\
$\mathrm{W}_{\mathrm{a}}$ & & & & & $\mathbf{4 . 8 3}$ \\
\hline
\end{tabular}

\section{Conclusions}

The purpose of this paper was to analyze the significance of each aggregate characteristic and determine the best combinations of factors which further influence the compressive strength and elastic modulus of RAC using the ANN model. The ANN model was trained and built on the basis of a series of experimental results including 46 concrete mixes. The research took eight factors into consideration as the inputs of the ANN model. The results are as follows. 
(1) The predicted results of RAC prepared with different sources of RAs were not satisfactory using the ANN models $\left(A N N_{6}-f_{c}\right.$ and $\left.A N N_{6}-E_{c}\right)$, although the learning abilities of these models were still good. This was because these ANN models only adopted the mix proportions and curing age as the input variables, without considering the aggregate characteristics of RA, which were quite different from the natural aggregate.

(2) The water absorption of RA played a most important role in affecting the compressive strength of RAC, the addition of which could reduce the error of $A N N_{6}-f_{c}$ from $8.11 \%$ to $6.03 \%$. The combination of specific gravity, water absorption and impurity content could further decrease the error to only about $5.43 \%$.

(3) As regards elastic modulus, characteristics like mortar content, aggregate crushing value and $10 \%$ fines value were proved to be not important in affecting the prediction. In addition to the mix proportions and curing ages, water absorption and specific gravity were the most significant aggregate characteristics. The addition of each of them as networks inputs could decrease the error to less than $4.85 \%$, and the network error could even be reduced to only about $3.89 \%$ when the inputs were a combination of mix proportions, curing time, specific gravity and water absorption of the coarse aggregate.

Author Contributions: Funding acquisition, C.-S.P. and Y.L.; Investigation, S.H. and J.X.; Methodology, Z.D. and C.-S.P.; Software, Y.L.; Writing-original draft, Z.D.

Funding: This research was funded by the National Natural Science Foundation of China (grant number 51708419) and Shanghai Pujiang Talent Fund (grant number 17PJ1409500).

Acknowledgments: The authors wish to acknowledge the financial support of the Hong Kong Polytechnic University and Sun Hung Kai Properties Ltd.

Conflicts of Interest: The authors declare no conflict of interest.

\section{References}

1. Kurda, R.; Silvestre, J.D.; Brito, J.D. Life cycle assessment of concrete made with high volume of recycled concrete aggregates and fly ash. Resour. Conserv. Recycl. 2018, 139, 407-417. [CrossRef]

2. Colangelo, F.; Petrillo, A.; Cioffi, R.; Borrelli, C.; Frcina, A. Life cycle assessment of recycled concretes: A case study in southern Italy. Sci. Total Environ. 2018, 615, 1506-1517. [CrossRef] [PubMed]

3. Colangelo, F.; Forcina, A.; Farina, I.; Petrillo, A. Life cycle assessment (LCA) of different kinds of concrete containing waste for sustainable construction. Buildings 2018, 8, 70. [CrossRef]

4. Silva, R.V.; Brito, J.D.; Dhir, R.K. Properties and composition of recycled aggregates from construction and demolition waste suitable for concrete production. Constr. Build. Mater. 2014, 65, 201-217. [CrossRef]

5. Poon, C.S.; Shui, Z.H.; Lam, L. Effect of microstructure of ITZ on compressive strength of concrete prepared with recycled aggregates. Constr. Build. Mater. 2004, 18, 461-468. [CrossRef]

6. Guo, Z.G.; Tu, A.; Chen, C.; Lehman, D.E. Mechanical properties, durability, and life-cycle assessment of concrete building blocks incorporating recycled concrete aggregates. J. Clean. Prod. 2018, 199, 136-149. [CrossRef]

7. Xiao, J.Z. Recycled Aggregate Concrete Structures; Spring: Berlin, Germany, 2018; pp. 65-97. ISBN 978-3662-53985-9.

8. Pedro, D.; Brito, J.D.; Evangelista, L. Durability performance of high-performance concrete made with recycled aggregates, fly ash and densified silica fume. Cem. Concr. Compos. 2018, 93, 63-74. [CrossRef]

9. Colangelo, F.; Cioffi, R. Mechanical properties and durability of mortar containing fine fraction of demolition wastes produced by selective demolition in south Italy. Compos. Part B 2017, 115, 43-50. [CrossRef]

10. Evangelista, L.; Brito, J.D. Durability of crushed fine recycled aggregate concrete assessed by permeability-related properties. Mag. Concr. Res. 2018. [CrossRef]

11. Rodríguez, C.; Miñano, I.; Aguilar, M.Á.; Ortega, J.M.; Parra, C.; Sánchez, I. Properties of Concrete Paving Blocks and Hollow Tiles with Recycled Aggregate from Construction and Demolition Wastes. Materials 2017, 10, 1374. [CrossRef] [PubMed] 
12. Kou, S.C.; Poon, C.S. Mechanical properties of 5-year-old concrete prepared with recycled aggregates obtained from three different sources. Mag. Concr. Res. 2008, 60, 57-64. [CrossRef]

13. Gonçalves, P.; Brito, J.D. Recycled aggregate concrete (RAC)-comparative analysis of existing specifications. Mag. Concr. Res. 2010, 62, 339-346. [CrossRef]

14. Jayasuriya, A.; Adams, M.P.; Bandelt, M.J. Understanding variability in recycled aggregate concrete mechanical properties through numerical simulation and statistical evaluation. Constr. Build. Mater. 2018, 178, 301-312. [CrossRef]

15. Hu, Z.; Mao, L.X.; Xia, J.; Liu, J.B.; Gao, J.; Yang, J.; Liu, Q.F. Five-phase modelling for effective diffusion coefficient of chlorides in recycled concrete. Mag. Concr. Res. 2017, 70, 583-594. [CrossRef]

16. Seo, D.S.; Choi, H.B. Effects of the old cement mortar attached to the recycled aggregate surface on the bond characteristics between aggregate and cement mortar. Constr. Build. Mater. 2014, 59, 72-77. [CrossRef]

17. Etxeberria, M.; Vazquez, E.; Mari, A.; Barra, M. Influence of amount of recycled coarse aggregates and production process on properties of recycled aggregate concrete. Cem. Concr. Res. 2007, 37, 735-742. [CrossRef]

18. Brito, J.D.; Robles, R. Recycled aggregate concrete (RAC) methodology for estimating its long-term properties. Indian J. Eng. Mater. Sci. 2010, 17, 449-462.

19. Tam, V.W.Y.; Tam, C.M. Parameters for assessing recycled aggregate and their correlation. Waste Manag. Res. 2009, 27, 52-58. [CrossRef] [PubMed]

20. Duan, Z.H.; Kou, S.C.; Poon, C.S. Prediction of compressive strength of recycled aggregate concrete using artificial neural networks. Constr. Build. Mater. 2013, 40, 1200-1206. [CrossRef]

21. Duan, Z.H.; Kou, S.C.; Poon, C.S. Using artificial neural networks for predicting the elastic modulus of recycled aggregate concrete. Constr. Build. Mater. 2013, 44, 524-532. [CrossRef]

22. Sensitivity Analysis. Available online: http://en.wikipedia.org/wiki/Sensitivity_analysis (accessed on 14 December 2017).

23. Coronado, C.A.; Lopez, M. Sensitivity analysis of reinforced concrete beams strengthened with FRP laminates. Cem. Concr. Compos. 2006, 28, 102-114. [CrossRef]

24. El-Dash, K.M.; Ramadan, M.O. Effect of aggregate on the performance of confined concrete. Cem. Concr. Res. 2006, 36, 599-605. [CrossRef]

25. Khatri, R.P.; Sirivivatnanon, V. Characteristic service life for concrete exposed to marine environments. Cem. Concr. Res. 2004, 34, 745-752. [CrossRef]

26. Jain, A.; Jha, S.K.; Misra, S. Modeling and analysis of concrete slump using artificial neural networks. J. Mater. Civ. Eng. 2008, 20, 628-633. [CrossRef]

27. Nikoo, M.; Sadowski, L.; Moghadam, F.T. Prediction of Concrete Compressive Strength by Evolutionary Artificial Neural Networks. Adv. Mater. Sci. Eng. 2015, 2015, 849126. [CrossRef]

28. Liang, C.; Qian, C.; Chen, H.; Kang, W. Prediction of compressive strength of concrete in wet-dry environment by bp artificial neural networks. Adv. Mater. Sci. Eng. 2018, 2018, 6204942. [CrossRef]

29. Parichatprecha, R.; Nimityongskul, P. Analysis of durability of high performance concrete using artificial neural networks. Constr. Build. Mater. 2009, 23, 910-917. [CrossRef]

30. Siddique, R.; Aggarwal, P.; Aggarwal, Y. Prediction of compressive strength of self-compacting concrete containing bottom ash using artificial neural networks. Adv. Eng. Softw. 2011, 42, 780-786. [CrossRef]

31. Chithra, S.; Kumar, S.R.R.S.; Chinnaraju, K.; Ashmita, F.A. A comparative study on the compressive strength prediction models for High Performance Concrete containing nano silica and copper slag using regression analysis and Artificial Neural Networks. Constr. Build. Mater. 2016, 114, 528-535. [CrossRef]

32. Sarıdemir, M.; Topçu, I.B.; Ozcan, F.; Severcan, M.H. Prediction of long-term effects of GGBFS on compressive strength of concrete by artificial neural networks and fuzzy logic. Constr. Build. Mater. 2009, 23, 1279-1286. [CrossRef]

33. Hodhod, O.A.; Ahmed, H.I. Developing an artificial neural network model to evaluate chloride diffusivity in high performance concrete. HBRC J. 2013, 9, 15-21. [CrossRef]

(C) 2018 by the authors. Licensee MDPI, Basel, Switzerland. This article is an open access article distributed under the terms and conditions of the Creative Commons Attribution (CC BY) license (http://creativecommons.org/licenses/by/4.0/). 